OPEN ACCESS

Edited by:

Polydefkis Hatzopoulos, Agricultural University of Athens,

Greece

Reviewed by:

Elena A. Vidal,

Pontificia Universidad Catolica de Chile, Chile

Hao Peng,

Washington State University, USA

*Correspondence:

Daniel Osuna

dosuna@ias.csic.es

Specialty section:

This article was submitted to

Plant Physiology,

a section of the journal

Frontiers in Plant Science

Received: 19 August 2015 Accepted: 05 November 2015 Published: 18 November 2015

Citation:

Osuna D, Prieto $P$ and Aguilar $M$ (2015) Control of Seed Germination and Plant Development by Carbon

and Nitrogen Availability.

Front. Plant Sci. 6:1023.

doi: 10.3389/fpls.2015.01023

\section{Control of Seed Germination and Plant Development by Carbon and Nitrogen Availability}

\author{
Daniel Osuna ${ }^{1 *}$, Pilar Prieto $^{1}$ and Miguel Aguilar $^{2}$ \\ ${ }^{1}$ Institute for Sustainable Agriculture, Agencia Estatal Consejo Superior de Investigaciones Científicas, Córdoba, \\ Spain, ${ }^{2}$ Área de Fisiología Vegetal, Facultad de Ciencias, Universidad de Córdoba, Córdoba, Spain
}

Little is known about the molecular basis of the influence of external carbon/nitrogen $(\mathrm{C} / \mathrm{N})$ ratio and other abiotic factors on phytohormones regulation during seed germination and plant developmental processes, and the identification of elements that participate in this response is essential to understand plant nutrient perception and signaling. Sugars (sucrose, glucose) and nitrate not only act as nutrients but also as signaling molecules in plant development. A connection between changes in auxin transport and nitrate signal transduction has been reported in Arabidopsis thaliana through the NRT1.1, a nitrate sensor and transporter that also functions as a repressor of lateral root growth under low concentrations of nitrate by promoting auxin transport. Nitrate inhibits the elongation of lateral roots, but this effect is significantly reduced in abscisic acid (ABA)-insensitive mutants, what suggests that ABA might mediate the inhibition of lateral root elongation by nitrate. Gibberellin (GA) biosynthesis has been also related to nitrate level in seed germination and its requirement is determined by embryonic ABA. These mechanisms connect nutrients and hormones signaling during seed germination and plant development. Thus, the genetic identification of the molecular components involved in nutrients-dependent pathways would help to elucidate the potential crosstalk between nutrients, nitric oxide (NO) and phytohormones (ABA, auxins and GAs) in seed germination and plant development. In this review we focus on changes in $\mathrm{C}$ and $\mathrm{N}$ levels and how they control seed germination and plant developmental processes through the interaction with other plant growth regulators, such as phytohormones.

Keywords: carbon, nitrogen, nitric oxide, abscisic acid, auxin, gibberellin, cytokinin

\section{INTRODUCTION}

A seed needs to integrate all the signals that represent its nutritional status in order to achieve germination when the appropriate nutrients conditions are present. Only when the right hormonal response takes place, seed germination is induced and seedlings become mature plants.

Nutrients are also known to influence seedling development and some processes may be mediated by the absolute levels of a particular sugar, such as glucose (Borisjuk et al., 1998) or sucrose (Borisjuk et al., 2002), whereas other processes may be related to metabolic events associated with the presence of carbohydrates at high concentrations, rather than the presence of high concentrations of carbohydrate per se (Krapp et al., 1993). Moreover, sugar-responsive pathways exhibit crosstalk with nitrogen-responsive pathways (Coruzzi and Bush, 2001; Coruzzi and Zhou, 2001). Therefore, $\mathrm{C} / \mathrm{N}$ balance seems to be crucial for the regulation of gene expression by carbohydrates and nitrogen 
(Lejay et al., 1999; Oliveira and Coruzzi, 1999; Zhuo et al., 1999; Zheng, 2009). In spite of the importance of $\mathrm{C} / \mathrm{N}$ balance signaling, the number of genes so far implicated in this process is scarce. Among these genes, NRT2.1 and NRT2.2 are highaffinity nitrate transporters in roots, particularly important under non-limiting nitrogen growth conditions (Orsel et al., 2002). GLR1.1, a putative glutamate receptor 1.1, connects carbon and nitrogen metabolism, ABA metabolism and water stress response in Arabidopsis (Kang et al., 2004). OSU1/QUA2/TSD2-encoded putative methyltransferase may act in cell wall biogenesis (Mouille et al., 2007) and is necessary for a normal response to C/N balance (Gao et al., 2008). Different targets of OSU1/QUA2/TSD2 would regulate pectin biosynthesis and responses to $\mathrm{C} / \mathrm{N}$ balance, thus connecting cell wall biogenesis and $\mathrm{C} / \mathrm{N}$ balance response (Zheng, 2009). OSU1 seems to work by down-modulating different pathways resulting in high or low $\mathrm{C} / \mathrm{N}$ responses. Alternatively it could work on a single pathway regulating several transcription factors in response to $\mathrm{C} / \mathrm{N}$ imbalance conditions (Zheng, 2009). Finally, it has been demonstrated the involvement of specific $\mathrm{ABA}$ and $\mathrm{SnRK} 1 \mathrm{~s}$ signaling pathways in $\mathrm{C} / \mathrm{N}$ response under ABI1 regulation (Lu et al., 2015). Therefore, for each identified molecular player it is essential to check whether there is a signal representing $\mathrm{C} / \mathrm{N}$ balance signal or the $\mathrm{C} / \mathrm{N}$ balance sensing network just results from the crosstalk between carbohydrates and nitrogen pathways.

Genes involved in metabolism, protein synthesis and degradation, RNA metabolism, signal transduction and hormones (auxin, gibberellin, cytokinin, ethylene, abscisic acid and brassinosteroids) pathways may play important roles in the $\mathrm{C} / \mathrm{N}$ balance or ratio response, and nutrients crosstalk has also been reported (Palenchar et al., 2004; Price et al., 2004; Scheible et al., 2004; Gutiérrez et al., 2007; Osuna et al., 2007). Additionally, $\mathrm{C} / \mathrm{N}$ signaling systems are subject to a "matrix effect" in which downstream responses are dependent upon cell-type plus developmental, metabolic, and/or environmental conditions (Coruzzi and Zhou, 2001).

This review is focused on the mechanisms underlying the regulation of seed dormancy, seed germination and seedling development by carbon and nitrogen nutrient balance. Specific $\mathrm{C}$ - and $\mathrm{N}$-regulatory pathways and $\mathrm{C} / \mathrm{N}$ interaction pathways controlling these developmental processes will be described and discussed.

\section{N-CONTROL OF DEVELOPMENT}

\section{Seed Dormancy and Germination}

Germination is classically described as a triphasic process determined by water relations. Phase I: the seed imbibes and resumes metabolism. Phase II: water uptake by the seed reaches a plateau and stays in a dormant state. Phase III: water uptake is resumed and the radicle emerges from the seed (Finch-Savage and Leubner-Metzger, 2006).

The depth of seed dormancy was inversely correlated to seed nitrate content, "endogenous nitrate" (Alboresi et al., 2005). Production of dormant seeds was inhibited in plants grown in high concentration of nitrate $(50 \mathrm{mM})$ during seed maturation when compared to plants grown under standard conditions $(10 \mathrm{mM}$ nitrate). The nia1/nia2 double mutant, which accumulates nitrate under standard conditions, produces seeds that are less dormant than WT seeds under identical conditions (Wilkinson and Crawford, 1993). Nitrate uptake by NRT1.1 was suggested to play a relevant role in dormancy regulation (Alboresi et al., 2005). One of the genes encoding nitrate reductase, $N R 1$, was highly expressed under conditions that break dormancy, including cold, light and nitrate (Finch-Savage et al., 2007). Unlike NR1, expression of $\mathrm{NiR}$ gene may depend on nitrate. However, dormancy release was not accompanied by increased transcript abundance of none of the seven (putative) glutamine synthetase (GS1) genes. Control of nitrate assimilation at the (post) translational level was also analyzed, and the nitrate reductase mutant $\mathrm{G}^{\prime} 4-3$ of Arabidopsis, with just $0.5 \%$ of the nitrate reductase activity of the corresponding wild type, was even less dormant than the wild type (Alboresi et al., 2005). Thus nitrate uptake and reduction to nitrite seems to generate a signal for dormancy breaking instead of just being a source of an essential nutrient.

Nitrate can enhance ABA catabolism and inhibit ABA synthesis (Ali-Rachedi et al., 2004). Addition of nitrate to dormant seeds resulted in less ABA content and supress de novo synthesis. Seed dormancy was broken by nitrate, nitrite and $\mathrm{CN}^{-}$through $\mathrm{NO}$ production and altered ABA sensitivity (Bethke et al., 2006a). As shown by Matakiadis et al. (2008), regulation of ABA degradation is more important than regulation of $\mathrm{ABA}$ synthesis for the control of seed dormancy by exogenous nitrate. They proposed that CYP707A2, a gene involved in ABA catabolism, could play a role in the control of seed ABA content by endogenous nitrate (Figure 1). In addition, other genes like NCED9 must be involved in the control of dormancy by nitrate, since cyp707a2 mutant seeds behaved as the wild-type under $10 \mathrm{mM}$ nitrate.

In Arabidopsis, there are two genes encoding nitrate reductase (NR), NIA1 and NIA2. NIA1, which is expressed at much lower level than NIA2, seems to be responsible for NO production in the context of ABA signaling (Bright et al., 2006). Recently, Lozano-Juste and León (2010) have demonstrated that NO production in Arabidopsis is mostly associated to NO biosynthesis mediated by NIA/NR and AtNOA1 (Nitric Oxide-Associated1). Seed dormancy, hypersensitivity to $\mathrm{ABA}$ during seed germination and establishment, as well as dehydration resistance, all showed a good correlation with an increasing deficiency in $\mathrm{NO}$ of nia1nia2, noa1-2, and nia1nia2noa1-2 plants.

In Arabidopsis and barley, NO seems to be an endogenous regulator of seed germination (Figure 1), since it can disrupt seed dormancy (Bethke et al., 2004b, 2006a,b; Libourel et al., 2006). A similar function for NO was suggested by Sarath et al. (2005) in warm-season $\mathrm{C}_{4}$-grasses. Switchgrass seeds responded positively to NO, and NO could disrupt the residual dormancy found in cold-stratified switchgrass seeds.

$\mathrm{NO}$ or KCN vapors induced germination in seeds lacking a testa, suggesting that NO was perceived in the aleurone cells or in the embryo. Aleurone layer perceived $\mathrm{NO}$ and responded to it because vacuolation was inhibited by the NO scavenger (Bethke et al., 2007), strongly suggesting that Arabidopsis aleurone cells synthesize NO. There are no evidences that NO is produced enzymatically. On the contrary, NO seems to be generated in the apoplast of the aleurone cell layer by non-enzymatic reduction of 


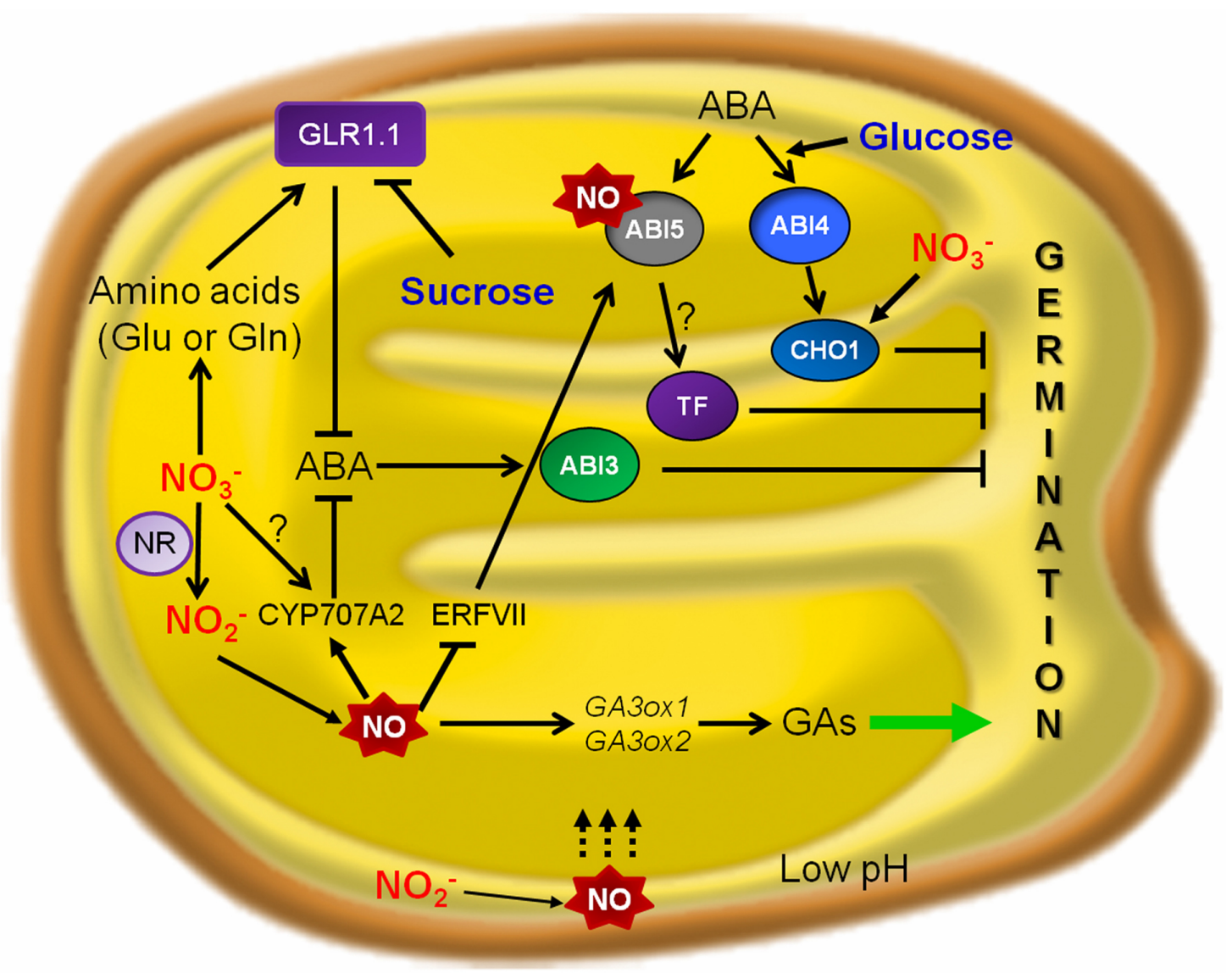

FIGURE 1 | A hypothesized model for nutrients signaling crosstalk with NO and ABA during seed germination. The figure highlights the action points of nitrate and glucose in NO and ABA signaling pathways controlling alleviation of seed dormancy and promotion of Arabidopsis seed germination. In the context of ABA-mediated inhibition of seedling establishment, NIA/NR- and AtNOA1-mediated pathways of NO biosynthesis function in an additive way. NO-deficient seedlings showed a higher basal and induced expression of ABA-responsive genes, conferring enhanced resistance to dehydration. In Arabidopsis, ABA $8^{\prime}$-hydroxylase encoded by CYP707A2 is implicated in NO-mediated ABA catabolism and seed dormancy break (Liu et al., 2009). In the seed endosperm, group VII ERFs act as NO sensors and regulate ABI5 (ABSCISIC ACID INSENSITIVE 5), highlighting as molecular players in NO-ABA crosstalk during seed germination (Gibbs et al., 2014). NO nitrosylates $\mathrm{ABI}$ as a regulator to control ABA hormone signaling through its degradation (Albertos et al., 2015). AtGLR1.1 is a component of the HXK1-independent ABA pathway and can be expressed in presence of a N source such as nitrate or amino acids (Glu or Gln), promoting seed germination (Kang and Turano, 2003; Kang et al., 2004). NR, nitrate reductase; NO, nitric oxide; ABA, abscisic acid; GAs, gibberellins; GA3ox1 and GA3ox2, Gibberellic acid oxidase1 and 2; CYP707A2, Cytochrome P450 ABA 8'-hydroxylase; GLR1.1, putative glutamate receptor 1.1; TF, transcription factor.

nitrite at acidic $\mathrm{pH}$ in germinating seeds, and catechin would also stimulate the production of NO from nitrite with a maximum at pH 3-4 (Bethke et al., 2004a,b). Nitrite either entering the grain from soil solution or released by the embryo axis, the scutellum, or the aleurone layer to the apoplast/endosperm cavity, would result in NO production (Bethke et al., 2004a), and apoplast of both GA- and ABA-treated Hordeum vulgare aleurone layers can produce NO from nitrite. NO would be an ideal signal for coordinating the activities of the embryo axis, scutellum, and aleurone layer in real time. Removal or damage of the aleurone layer resulted in embryo growth, demonstrating that one function of the Arabidopsis aleurone layer is to maintain the dormancy of imbibed seeds.

In Arabidopsis thaliana seeds, sodium nitro-prusside, cyanide, nitrate and nitrite decreased dormancy and the NO scavenger cPTIO effectively promoted the maintenance of seed dormancy (Bethke et al., 2006b). NO was required to complete dormancy loss initiated by nitrate or nitrite, and cPTIO maintained dormancy in nitrite- and nitrate-treated seeds. Experimental data from Libourel et al. (2006) showed that exogenous gaseous NO is sufficient to disrupt seed dormancy. Cadman et al. (2006) have also suggested that, in Arabidopsis, the transcriptome anticipates growth initiation during dormancy-breaking. An increased NR1 transcript abundance would anticipate nitrate assimilation during seedling growth. In switchgrass, however, seed germination was not significantly stimulated by nitrite or nitrate alone, and ferrocyanide was more effective than cyanide (Sarath et al., 2005).

GAs promote germination (Yamaguchi and Kamiya, 2002) and GA deficient mutants fail to germinate (Ross et al., 1997). The importance of ABA/GA balance for germination is supported by the fact that the reduced dormancy of some of the ABA mutants was linked to a lower GA-requirement for germination (Koornneef et al., 2002). GAs promote rapid degradation of DELLA proteins (intracellular repressors of GA responses), which 
leads to activation of the signaling pathway, and the comparison of gene expression in ga1-3. In DELLA-domain protein-deficient mutants ( $g a i, r g a, r g l 1$, and $r g l 2$ ) in the gal-3 background allows to suggest the existence of DELLA-dependent and -independent gene expression pathways during germination (Cao et al., 2006). NO is also necessary for the transcription of GA3ox1 and GA3ox2 genes, involved in the biosynthesis of GA, which is needed for the vacuolation of cells in isolated aleurone layers in the absence of NO (Bethke et al., 2007). This suggests the possibility that NO could coordinate the reduction of dormancy imposed by ABA with the initiation of germination stimulated by GA (Figure 1). Hydroxylamines, nitrites, and other nitrogenous compounds yielding NO under strong oxidation are the striking promotors for germination of some kinds of seeds (Hendricks and Taylorson, 1974).

\section{Root and Shoot Development}

Plants have mechanisms for sensing nitrate as a signal for inorganic- $\mathrm{N}$ status, whereas metabolites derived from nitrate may serve as signals for organic- $\mathrm{N}$ status. It is also known than nitrogen sensing regulates phenotypic changes in plants. Nitrateactivated transcription of a set of genes is related to the positive regulation of nitrate transport, whereas ammonium or glutamine have been proposed to negatively regulate this process (Touraine, 2004). A root-specific ANR1 gene (a member of the MADS box transcription factors family), is nitrate-induced and appears to control lateral root growth (Zhang and Forde, 1998). There are examples of control by nitrogen both at the transcriptional and post-transcriptional level, and also examples of the matrix effect (Coruzzi and Zhou, 2001).

In a nitrate re-addition experiment to Arabidopsis liquid cultures transcriptional reprogramming of hormone metabolism and sensing was identified as one of the early responses to nitrate addition (Scheible et al., 2004). Several genes involved in CK synthesis, including IPT3 and several downstream response elements involved in CK signaling, were induced around $30 \mathrm{~min}$ after adding $3 \mathrm{mM}$ nitrate $\left(\mathrm{KNO}_{3}\right)$, and other genes associated with CK signaling were up-regulated after $3 \mathrm{~h}$. DF4, a gene involved in brassinosteroid biosynthesis and other genes involved in GA synthesis were also up-regulated after $3 \mathrm{~h}$. Many 1-aminocyclopropane-1-carboxylate oxidases and other genes involved in ethylene synthesis and sensing were repressed.

ABA-insensitive mutants (abi4-1, abi4-2, and abi5) suffer a reduction of the systemic inhibitory effect of nitrate (Signora et al., 2001). Among other features of their phenotype, they show an increased elongation of lateral root at high concentrations of nitrate, what suggests that $\mathrm{ABA}$ is an important mediator of the inhibitory effect of nitrate on lateral root elongation. In Arabidopsis, nitric oxide (NO) can reduce primary root growth and also induce lateral root development, both processes being also regulated by auxins. In $A$. thaliana there is also an anthocyanin biosynthesis pathway that is specifically induced by nitrate limitation, in which pathway NLA (Nitrogen Limitation Adaptation) is an essential molecular component (Peng et al., 2008).

Auxins are essential for plant root development, and both shoot- and root-synthesized auxins contribute to root organization and development. Shoot-derived auxins move to root cells by diffusion, a mechanism that differs from the mechanism of directing auxin distribution through polar auxin transport (PAT) occurring in roots. The same pathway that is followed by carbohydrates from "source to sink" also enables the long-distance flow of auxin and other hormones such as ABA and cytokinins (Robert and Friml, 2009). A good number of genes involved in auxin biosynthesis are expressed in roots, and the auxin that is generated in roots is partly responsible for the gradients that are necessary for normal root development (Ljung et al., 2005; Ikeda et al., 2009; Petersson et al., 2009). Auxin signaling comprises a number of molecular components and works by stabilizing the interaction of the TRANSPORT INHIBITOR RESPONSE 1 (TIR1) protein or the AUXIN FBOX PROTEINs (AFBs) with proteins of the Aux/IAA family (Overvoorde et al., 2010; see Figure 2). TIR1 and AFB proteins contribute to substrate specificity for the E3 ubiquitin-ligase activity of Skp1-Cul1-F-box (SCF) complexes (Chapman and Estelle, 2009). The IAA-stabilized interaction of SCF (TIR or AFB) enables Aux/IAA ubiquitination and the action of the 26S proteasome to remove these proteins (Maraschin Fdos et al., 2009).

Nitric oxide treatment affects meristem size in the primary root mainly by decreasing cell-division rates and promoting cell differentiation (Figure 2; Fernández-Marcos et al., 2011). A reduction in meristem size was also observed in the NO overaccumulating mutant chlorophyll $\mathrm{a} / \mathrm{b}$ binding protein underexpressed 1/NO overproducer 1 (cue1/nox 1 ). Interestingly, the root apical auxin maximum is altered after NO addition. Auxin transport and the level of the auxin efflux protein PINFORMED 1 (PIN1) are reduced significantly in the cuel/nox 1 double mutant. The abnormal organization of the quiescent center and surrounding cells of cue1/nox 1 double mutants resembles the phenotype of pin1-mutant roots, what suggests a connection between $\mathrm{NO}$ and auxin signaling in maintaining the activity and the size of the root apical meristem (Fernández-Marcos et al., 2011).

Changes in NR levels during plant growth modify NO levels and would link metabolism to gene regulation, and NO derived from NR activity modulates group VII ERF transcriptional regulators stability through targeted proteolysis (N-End Rule Pathway in plants; Gibbs et al., 2014). Still it is necessary to check if, similarly to seed germination, group VII ERFs regulate $\mathrm{NO} / \mathrm{ABA}$ signaling by controlling the expression of $A B I 5$ ( $A B A$ INSENSITIVE 5) in seedlings grown under different $\mathrm{C} / \mathrm{N}$ regimes.

Nitrogen nutrition has significant effects on root and shoot relations (Feng and Liu, 1996; Lioert et al., 1999). Nitrogen deficiency increased root surface area, increased consumption of assimilates, reduced the amount of nitrogen translocated to shoot, diminished shoot growth, and yielded an increased root/shoot ratio. Extra nitrogen nutrition, however, caused a shoot overgrowth, reduced the amount of assimilates availability for root, and decreased the root/shoot ratio (Passioura, 1983).

All in all, root growth regulation could be summarized as follows: auxin flows from the lateral root cap to the basal meristem and returns to the root tip (Overvoorde et al., 2010). Nitrate is reduced to nitrite by nitrate reductase in the root. NIA/NR- 


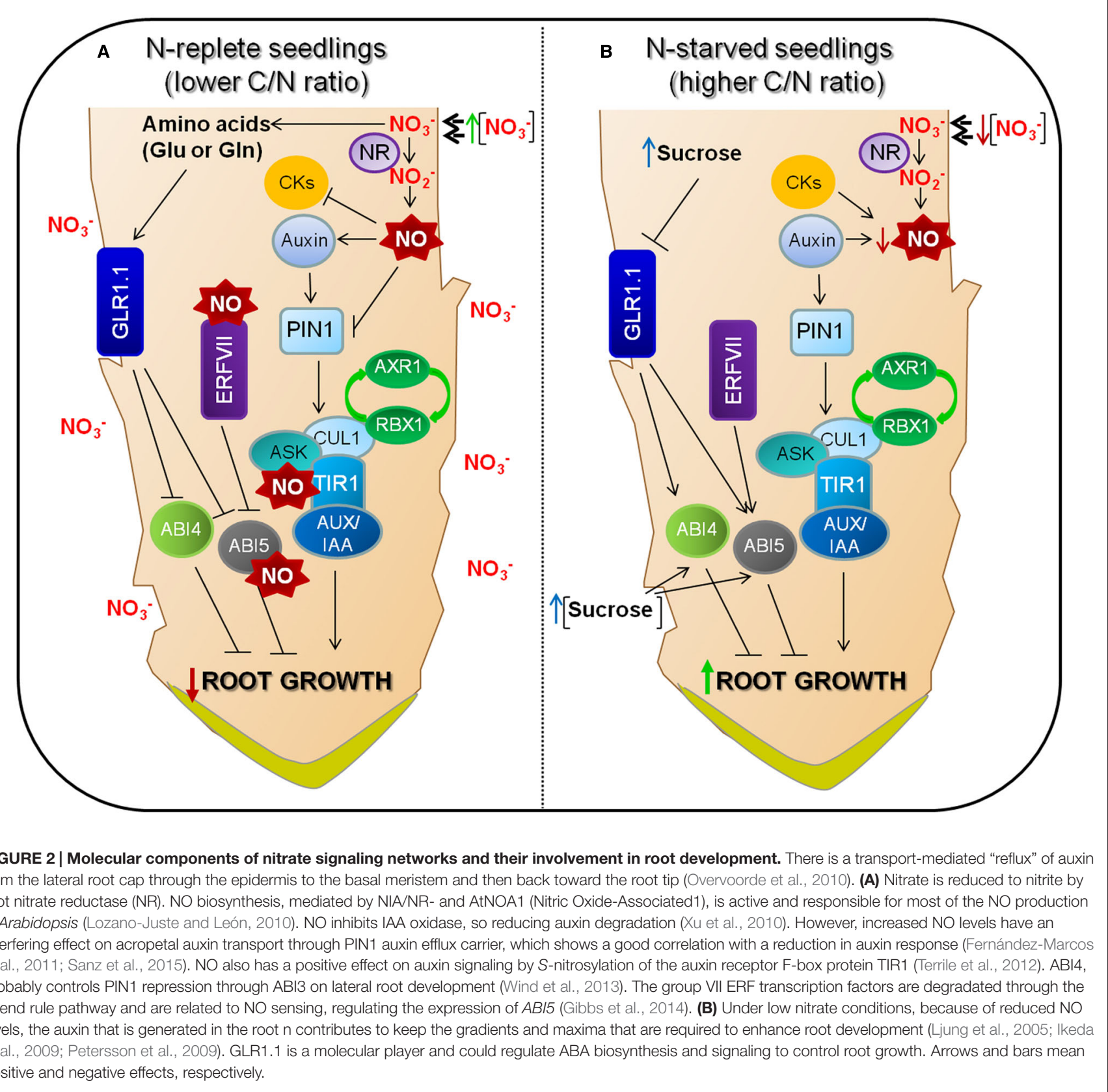

and AtNOA1 (Nitric Oxide-Associated1)-mediated synthesis of $\mathrm{NO}$ is active and generates most of the NO in Arabidopsis (Lozano-Juste and León, 2010). NO maintains auxin levels by inhibiting IAA oxidase activity (Xu et al., 2010), but high NO interfere with acropetal auxin transport through PIN1 auxin efflux carrier, which correlates well with a reduced response to auxin (Fernández-Marcos et al., 2011; Sanz et al., 2015). NO also has a positive effect on auxin signaling through $S$-nitrosylation of TIR1 (Terrile et al., 2012). In N-replete seedlings (lower $\mathrm{C} / \mathrm{N}$ ratio condition), increased NO levels would nitrosylate ABI5 as a regulator to control $\mathrm{ABA}$ hormone signaling through its degradation (Albertos et al., 2015). On the other hand, ABI5 is stabilized through its phosphorylation upon $\mathrm{ABA}$ treatment becoming active (Hu et al., 2014). Therefore, characterization of ABI5 post-translational modifications is relevant, and it bound to NO interference on acropetal auxin transport through PIN1 auxin efflux carrier, establishes a limited root development (Figure 2A). Under low nitrate conditions, because of reduced NO levels, the auxin that is generated in the root contributes to maintain the gradients and maxima required for enhanced root development (Ljung et al., 2005; Ikeda et al., 2009; Petersson et al., 2009). Additionally, in $\mathrm{N}$-starved seedlings, auxin and cytokinins (CKs) could increase NO production to basal levels, similar to other stresses such as iron deficiency (Chen et al., 2010). CKs are known to induce NO biosynthesis depending on plant cell status (Yu et al., 1998), and auxins could increase NO production 
similarly to other stresses such as iron deficiency (Chen et al., 2010). These minimum NO levels would not be enough to repress PIN1 expression, not altering acropetal auxin transport, therefore promoting enhanced root growth (Figure 2B). It seems that low NO levels generated in $\mathrm{N}$-starved root seedlings (higher $\mathrm{C} / \mathrm{N}$ ratio) are determinants for enhanced lateral root growth rate (Figure 2B). Moreover, ABI5 post-translational state could regulate their downstream transcription factors in an exquisite way, causing an effect in metabolism, growth and plant development.

\section{C-CONTROL OF DEVELOPMENT}

\section{Seed Dormancy and Germination}

In Arabidopsis seeds, dormancy release can be activated by cold, nitrate and light. The efficiency of this activation depends on the extension of the dry after-ripening period following harvest (Finch-Savage et al., 2007). Light is essential for germination, though dormancy is not released by light if seeds have not been subject to an extended period of after-ripening or a combination of a shorter period of after-ripening plus imbibition on a nitrate solution or cold treatment.

Regulation of seed germination under an excess of nutrient supply has also been deeply studied. CHO1 codes for a putative transcription factor with two AP2 domains, expressed predominantly in seed, with the strongest expression $24 \mathrm{~h}$ after seed imbibition. Under an excess of glucose an nitrate supply, ABA signaling pathway could be influenced at different levels, and transcription factor CHOTTO1 (a double APETALA2 domain protein of Arabidopsis thaliana) is responsible for germination arrest (Yamagishi et al., 2009). Arabidopsis cho1 mutants are resistant to the ABA analog (-)-R-ABA during seed germination and seedling development (Yamagishi et al., 2009). Only weak resistance to exogenously applied (+)-S-ABA was observed during seed germination of chol seeds, and abi4 chol double mutant seeds germinated at rates comparable to those of the abi4-5 mutant seeds in the presence of exogenous (+)-S-ABA. Moreover, the induction of $\mathrm{CHO} 1$ expression did not occur in the abi4 mutants, suggesting that $\mathrm{CHO}$ acts in the same pathway as ABI4. ABI4 is involved in glucose signaling, and therefore operates the downstream target $\mathrm{CHO} 1$. As a result, both abi4 and cho1 mutants exhibit growth resistance to high concentrations of glucose. In contrast, $\mathrm{CHO} 1$, but not $\mathrm{ABI} 4$, is required for inhibition by excess of nitrate (Figure 1). The inhibitory action of different sugars on seed germination could proceed through different pathways, including complex interactions with those on phytohormone-response. A high level of glucose is responsible for the induction of ABA synthesis and also induces the expression of $A B I 4$ and $A B I 5$. This suggests that at least some aspects of sugar signaling may be mediated by ABA response (Arroyo Becerra et al., 2001). Furthermore, glucose hypersensitivity results by overexpressing $\mathrm{ABI} 3, \mathrm{ABI}$, or $\mathrm{ABI}$, what suggests that these $\mathrm{ABI}$ genes could mediate the response to $\mathrm{ABA}$ and sugar (Finkelstein et al., 2002); in fact, the induction of these $A B I$ genes is stronger when glucose is added to the medium during early stages of seedling development, right when the plant is most sensitive to the inhibitory effects of sugar (Gibson et al., 2001) and ABA induces ABI5 accumulation (Lopez-Molina et al., 2001). In Lotus japonicus, at concentrations up to $200 \mu \mathrm{M}$, nitrite and nitrate alleviated glucose-induced delay of seed germination, in a $\mathrm{NO}$ mediated response (Zhao et al., 2008).

Several sugars may delay seed germination via different pathways. Price et al. (2003) showed that glucose modulates a decreased in ABA concentration during germination in wildtype Arabidopsis seeds (Figure 1). Seed germination of Lotus japonicus was reported to be delayed by exogenous glucose (Zhao et al., 2008) and there was a significant inhibitory effect on seed germination with $2.5 \%$ glucose after $72 \mathrm{~h}$. Inhibition of seed germination by glucose was substantially alleviated by exogenous supply of SNP (sodium nitroprusside), an exogenous donor of NO, (2.5\% glucose $+200 \mu \mathrm{M}$ SNP), and this effect was significantly reduced by cPTIO [carboxy-PTIO, 2-(4carboxyphenyl)-4,4,5,5-tetramethylimidazoline-1-oxyl-3-oxide], a NO scavenger $(200 \mu \mathrm{M})$, suggesting that the effect of SNP is likely due to NO. Germination of Lotus japonicus seeds was insensitive to $\mathrm{KNO}_{2}$ and $\mathrm{KNO}_{3}$ at concentrations up to $200 \mu \mathrm{M}$ in the absence of glucose. At these concentrations, nitrite and nitrate alleviated glucose-induced delay of seed germination.

Auxins have been involved in cell-wall remodeling (Swarup et al., 2008), and imbibed after-ripened seeds, showed an enhanced expression of genes related to RNA translation, protein degradation and cell wall modification than dormant seeds (Holdsworth et al., 2007), and the expression of these genes increases within 1 and $3 \mathrm{~h}$ in imbibed after-ripened seeds (Nakabayashi et al., 2005). Genes involved in auxin transport (AUX1, PIN1, PIN7) are highly upregulated following imbibition of after-ripened seeds (Cadman et al., 2006; Carrera et al., 2007) or addition of gibberellin (GA; Ogawa et al., 2003), suggesting the initiation of root growth at the onset of phase III.

In short, seed germination is controlled by nutrient status through multiple action points. This implies a bona fide perception of nutrient balance, acting through signaling pathways either repressing or promoting seed germination.

\section{Root and Shoot Development}

C-status ultimately controls many aspects of plant development. Vegetative growth is controlled by the cellular metabolic status (Lastdrager et al., 2014). Sugars are long-distance signals and there are sugar-dependent regulatory networks in roots. SnRK1 is a growth inhibitor under nutrient stress conditions (Guérinier et al., 2013). Sugar-phosphates regulate plant SnRK1 (Ghillebert et al., 2011). Glucose-6-phosphate (G6P), glucose-1-phosphate (G1P), and trehalose-6-phosphate (T6P) are repressors of SnRK1 activity (Zhang et al., 2009). Sucrose promotes the accumulation of T6P by inhibiting SnRK1 activity, thereby inducing biosynthetic processes and plant growth. Plant SnRK1 controls several important enzymes, such as nitrate reductase and sucrose phosphate synthase (Purcell et al., 1998). This suggests that SnRK1 could play a relevant role in controlling $\mathrm{C} / \mathrm{N}$ metabolism (Coruzzi and Zhou, 2001). The ABA effect could be related to SnRK1, since phosphatases implicated in ABA signaling seem to inhibit SnRK1 activity through SnRK1 dephosphorylation (Rodrigues et al., 2013). Arabidopsis group C/S1 basic leucine zipper (bZIP) consists of nine bZIP transcription factors network and depends on the 
presence of bZIP proteins in a particular cellular context. The $\mathrm{C} / \mathrm{S} 1$ network of bZIP factors works efficiently to integrate signals (Weltmeier et al., 2009). All these bZIP factors are expressed specifically in sink organs like young leaves, anthers and seeds. This fact suggests that the C/S1 network is involved in nutrients allocation to sink organs (Rook et al., 1998a,b). Sucrose inhibits the translation of S1-group bZIP mRNAs. The SnRK1 pathway has been assigned the function of adjusting the growth and development of the plant to its energy status (Baena-González et al., 2007). The SnRK1 pathway increases the transcriptional potential of S1 class bZIP proteins (Weltmeier et al., 2009) and SnRK1 seems to be implicated in the down-regulation of ribosomal protein (Baena-González et al., 2007). In a high metabolic status, T6p inhibits SnRK1, and the active TOR kinase stimulates translation and growth, being important for S1-group bZIP protein synthesis capacity via effects on ribosome biogenesis, mRNA polysome loading and mRNA translation (Rook et al., 1998a; Schepetilnikov et al., 2013).

Sucrose-induced repression of translation (SIRT) of the S1group bZIP transcription factors has been confirmed for all five Arabidopsis S1-group members (Rook et al., 1998a; Wiese et al., 2005; Weltmeier et al., 2009). Sucrose stimulates the activation of the AKIN complex in Arabidopsis (Bhalerao et al., 1999) and plant SNF1 may mediate the activation of gene expression by sucrose and glucose (Purcell et al., 1998; Bhalerao et al., 1999). PRL1 is a potential subunit of the Arabidopsis AKIN complex and is a putative negative regulator of AKIN, yet the mutant is hypersensitive toward glucose (Nemeth et al., 1998). Two Arabidopsis protein kinases, KIN10 and KIN11, seem to be involved in the control of transcription convergent reprogramming as a response to darkness, sugar and stress conditions, three apparently unrelated factors; in addition, specific bZIP transcription factors partially mediate primary KIN10 signaling. KIN10 targets promote catabolism and suppress anabolism by sensing and signaling sugar and energy deprivation (Baena-González et al., 2007).

Hexokinases play an important role in a hexokinase-dependent sugar response pathway (Moore et al., 2003). Several glucose signal transduction pathways are known: a first one is AtHXK1dependent, a second one is glycolysis-dependent and influenced by AtHXK1 activity, and a third pathway that is AtHXK1independent (Xiao et al., 2000). The hexokinase-signaling pathway might play a role in cell-cycle control linked to the carbohydrate status, and sugar regulation of cycD2 seems to be mediated by hexokinase (Riou-Khamlichi et al., 2000). Arabidopsis HXK1 plays a relevant role in a number of glucose responses, namely cell proliferation, root and inflorescence growth, leaf expansion and senescence, and reproduction. HXK1 can play different functions in glucose signaling and metabolism; in fact, many of these new HXK1 functions can be performed at least partially by catalytically inactive HXK1 mutants (Moore et al., 2003). Growth promotion or inhibition by HXK1 would depend on glucose concentration, cell type, developmental state, and environmental condition (Moore et al., 2003). In the absence of nitrate, low glucose level signaling is HXK1 mediated but is independent of ABA and ethylene signaling. At low glucose levels, $A B I 4$ and $A B I 5$ gene expression is HXK1 dependent, while at high glucose levels these genes are expressed independently of HXK1 (Cho et al., 2010).

Sucrose effects on auxin levels are more pronounced in roots than in shoots, suggesting that sugars may impact auxin transport and/or conjugation pathways as well (Ljung et al., 2015). Auxins and CKs present links to sucrose sensing and signaling, and can function as short- and long-distance signaling molecules. They can play a role in integration of growth and development between shoot and root (Ljung et al., 2015). The rapid response around 30 min after adding $15 \mathrm{mM}$ sucrose to C-starved seedlings, of an Aux/IAA family member IAA5 (Abel et al., 1995) is indicative of early crosstalk with auxins (Osuna et al., 2007). Auxin biosynthesis is induced by soluble sugars, and daily fluctuations in sugar content are correlated with fluctuations in auxin levels (Sairanen et al., 2012). In Arabidopsis, exogenous sucrose or glucose supply triggers an over-accumulation of auxin and increases the auxin flux in the hypocotyl notably through the up-regulation of the genes encoding auxin biosynthetic enzymes, including CYP79B2/3 and YUCCA8/9 (Lilley et al., 2012; Sairanen et al., 2012). Sucrose supplementation, required for rhythmic hypocotyl elongation, induces YUCCA9 in shoots but not roots and sucrose effects on auxin levels are more pronounced in roots than in shoots, suggesting that sugars may impact auxin transport and/or conjugation pathways as well (Ljung et al., 2015). Auxins and sugars can be transported from shoot to root, inducing lateral root development in order to increase water and nutrients uptake from the soil, in turn increasing shoot growth capacity (Ljung et al., 2015).

CKs regulate the expression of sucrose transporters involved in phloem unloading adjusting sugar partitioning and sink strength, and they also regulate invertases and hexose transporters involved in sucrose catabolism and uptake in sink tissues (Roitsch and González, 2004; Proels and Roitsch, 2009).

Sugars like trehalose 6-phosphate (Tre6P) is both a signal of sucrose status and a negative feedback regulator of sucrose levels (Yadav et al., 2014; Figure 3). Tre6P can affect developmental processes such as shoot branching. The impact of sugar during the systemic regulation of bud outgrowth in response to either decapitation or light intensity has been analyzed by Barbier et al. (2015). Axillary buds outgrowth is driven by sugar availability independently of auxin levels. The combination of high sugar levels in shoot and high sugar sink strength in buds (high photosynthesis rate) drives to high branching. Sugars play a signaling role, and not only a trophic role (Barbier et al., 2015).

Slower growth at night in the starchless mutant, which shows higher sucrose levels during the day and absence of sugars at the end of the night (Wiese et al., 2007), requires an adjustment of GAs level to match the lower growth potential deriving from the lack of sugars at night (Paparelli et al., 2013). The dwarfism of GA-deficient mutants is, instead, uncoupled from carbon availability (Ribeiro et al., 2012), indicating that GA is primarily required for growth. DELLA proteins seem to represent a point of convergence for the hormonal and sucrose-dependent regulatory networks and DELLA are involved in the sucroseGA interaction (Loreti et al., 2008; Figure 3). Sucrose-dependent stabilization of DELLAs (Li et al., 2014) seems to be a simple mechanism to connect sugars with other signaling pathways 


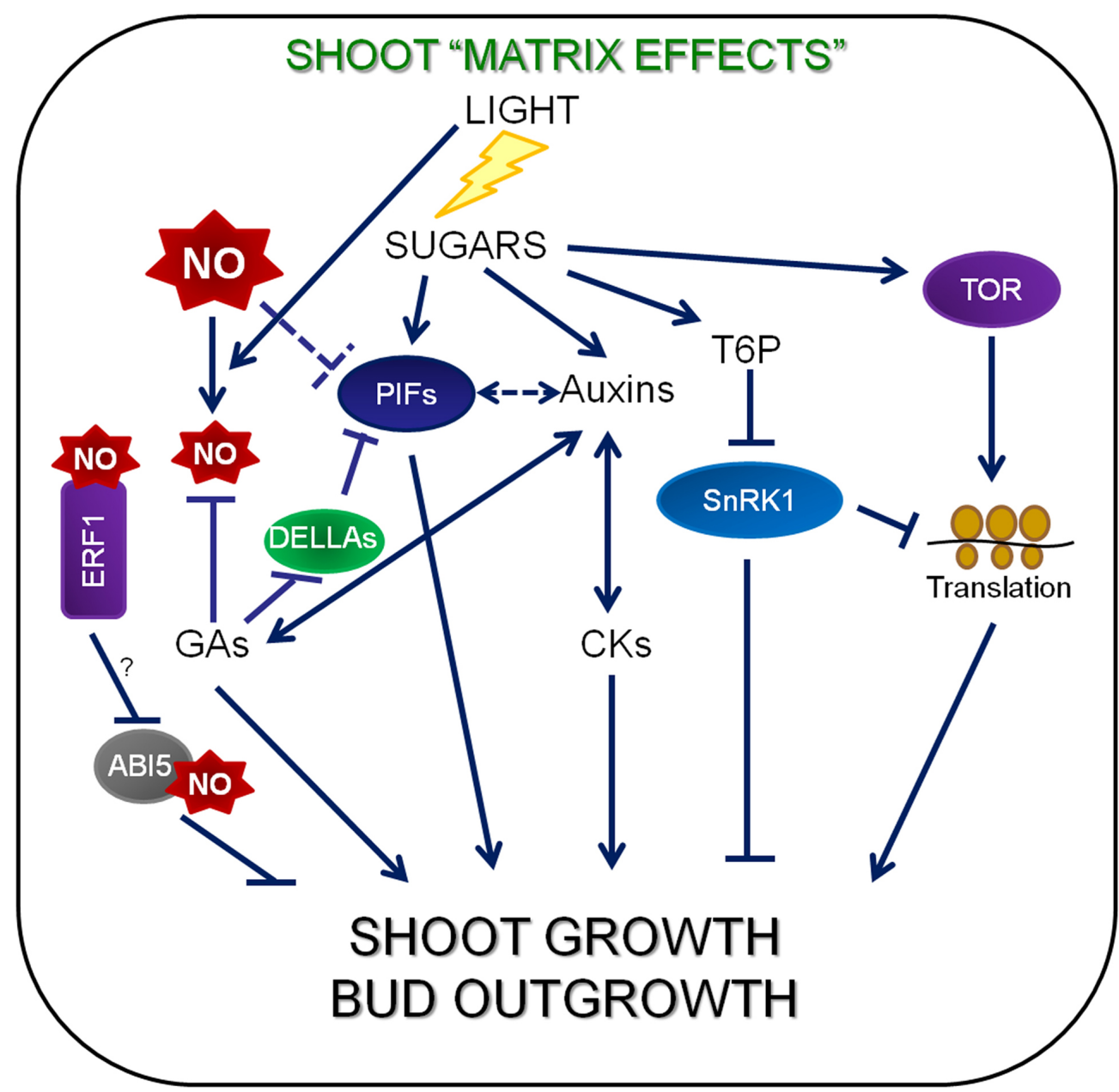

FIGURE 3 | Molecular components of sugar signaling networks and their involvement in shoot growth. CKs, auxins and sugars function as long-distance signals. When photosynthesis takes place, sugars content increase in shoot and low sugars in roots implies that GAs are transported from the roots to the shoots and send sugars to the low sugar roots. Sucrose availability (high metabolic status) shows a good correlation with the level of plant T6P, which acts as an inhibitor of SnRK1. The active TOR kinase is important for C/S1-group bZIP protein synthesis and enhances translation and growth. Sucrose down-regulates the expression of C/S1-group bZIP at the translation level and the C/S1-bZIP transcription factor network is involved in the regulation of SnRK1 target genes (Lastdrager et al., 2014). The repression of ribosomal protein gene expression by SnRK1 (Baena-González et al., 2007) inhibits translation. Sucrose effects on auxin levels are more pronounced in roots than in shoots, suggesting sugars may impact auxin transport and/or conjugation pathways as well. DELLA and PIF proteins are good candidates for molecular hubs operating at the crossroads of many pathways (Ljung et al., 2015). There are NO and GA antagonist functions in the control of light-regulated photomorphogenesis through the balance between DELLAs and PIFs (Lozano-Juste and León, 2011). ERF1 has been suggested to function in light-regulated control of hypocotyl elongation, in a different way to the Cys-Arg/N-end rule pathway (Zhong et al., 2012).

(Ljung et al., 2015). Cell expansion in the elongation zone of growing roots is controlled by GA, and the endodermis plays a key role in this process. Growth of these root tissues is regulated by endodermis-specific removal of DELLA repressor proteins mediated by GA, ensuring that cells from all elongation zones respond similarly to GAs expanding at the same rate (UbedaTomás et al., 2008).

The Phytochrome-Interacting Factor (PIF) family of transcription factors seem to have their basic helix-loophelix in every process involving light, temperature and growth (De Lucas and Prat, 2014). DELLA and PIF proteins are good candidates for molecular hubs operating at the crossroads of many pathways (Ljung et al., 2015; Figure 3). PIFs attenuate the light signal through negative feedback on phytochrome transcription, as well as by bringing them along when they are targeted for proteasome-mediated degradation (Ni et al., 2014). A combination of circadian clock and light regulation control the activity of PIF4 and PIF5, leading to predictable daily oscillations in seedling growth rates (Nozue et al., 2007). These PIF-driven growth cycles depend on supplying seedlings with exogenous sucrose (Liu et al., 2011; Stewart et al., 2011; Figure 3).

Nitric oxide regulates GA signaling by controlling DELLA abundance and function. Lozano-Juste and León (2011) suggested that NO could induce the accumulation of DELLAs, despite finding no transcriptional induction of DELLA genes. There are $\mathrm{NO}$ and GA antagonist functions in the control of light-regulated 
photomorphogenesis through the balance between DELLAs and PIFs (Lozano-Juste and León, 2011; Figure 3).

A sugar-sensing pathway has been discovered in cultured Arabidopsis cells: protein phosphorylation, 14-3-3 binding, and regulatory proteolysis control diverse target proteins in $\mathrm{C} / \mathrm{N}$ metabolism and signaling. Several cytosolic enzymes involved in $\mathrm{C} / \mathrm{N}$ metabolism (nitrate reductase, glutamine synthetase, sucrose-phosphate synthase, trehalose-6-phosphate synthase and glutamyl tRNA synthetase) are relevant targets of this pathway (Cotelle et al., 2000; Finnemann and Schjoerring, 2000). We must consider the matrix effect, since phosphorylation and 143-3 binding of distinct subsets of these enzymes seem to be regulated by photosynthesis and hormones (Coruzzi and Zhou, 2001). When cells are starved of metabolizable sugars, 14-3-3binding is lost and its targets are clipped by a specific cysteine protease.

Further studies are required to elucidate the signals responsible for nutrient signaling pathways in the regulation of root and shoot growth. CKs, auxins, GAs and sugars function as long-distance signals and a low level of sugar in roots implies that GAs are transported from the roots to the shoots. Sucrose availability, which implies a high metabolic status, is correlated with plant T6P levels and T6P inhibits SnRK1. It is known that metabolic events associated with a high concentration of carbohydrates could be crucial rather than the high concentrations of carbohydrate (Krapp et al., 1993). Additionally, the balance between DELLAs and PIFs is suggested to control light-regulated photomorphogenesis (Lozano-Juste and León, 2011).

\section{AND N INTERACTION PATHWAYS (C/N BALANCE)}

$\mathrm{C} / \mathrm{N}$ signaling systems are influenced by the biological context such as cell-type, developmental, metabolic, and/or environmental conditions, as already suggested by Coruzzi and Zhou (2001).

As previously mentioned, only a few genes involved in $\mathrm{C} / \mathrm{N}$ balance response have been described. NRT2.1 and NRT2.2 are the main high-affinity nitrate transporters in roots under N-replete conditions (Orsel et al., 2002). In their absence, an additional loss of function of NRT2.4 has a significant impact on plant fresh weight in $\mathrm{N}$-starved plants suggesting a complex interaction between them in response to changes in $\mathrm{N}$ availability (Kiba et al., 2012). NRT2.1 is also known to play a role in the repression of lateral root initiation under high sucrose/low nitrate context, acting as either a sensor or a signal transduction protein in low nitrate conditions (Little et al., 2005). However, additional studies are required in order to elucidate how NRT2.1 regulates pericycle cell divisions in function of $\mathrm{C} / \mathrm{N}$ external balance.

GLR1.1 (putative glutamate receptor 1.1) functions as a molecular regulator in the high $\mathrm{C} /$ low $\mathrm{N}$ response and its consequent implication in ABA metabolism and sensitivity, and response to water stress in Arabidopsis. AtGLR1.1 is a component of the HXK1-independent ABA pathway in germinating seeds and functions as a sensor pointing its true ligand to the Glu. GLR1.1 can be expressed in the presence of a $\mathrm{N}$ source such as nitrate or amino acids (Glu or Gln), promoting seed germination (Kang and Turano, 2003; Kang et al., 2004).

OSU1/QUA2/TSD2 encodes a putative methyltransferase which acts in cell wall biogenesis (Mouille et al., 2007) and is required for normal $\mathrm{C} / \mathrm{N}$ nutrient balance response in plants ( $\mathrm{GaO}$ et al., 2008). OSU1/QUA2/TSD2 might have different targets which in turn regulate pectin biosynthesis and $\mathrm{C} / \mathrm{N}$ balance responses, respectively. This represents a surprising link between cell wall biogenesis and C/N balance response (Zheng, 2009). OSU1 is likely to act as a negative modulator either in distinct pathways leading to high $\mathrm{C} / \mathrm{N}$ ratio or low $\mathrm{C} / \mathrm{N}$ ratio responses or in a single pathway regulating various transcription factors in response to these distinct $\mathrm{C} / \mathrm{N}$ imbalance conditions (Zheng, 2009).

Ubiquitin ligases are known to play an essential role in $\mathrm{C} / \mathrm{N}$ balance, mediating nutrient-responsive pathways. KEEP ON GOING (KEG), a RING-type ubiquitin ligase in Arabidopsis, localizes to trans-Golgi network/early endosome (TGN/EE) vesicles and adjusts $\mathrm{ABI} 5$ levels by poly-ubiquitination in function of $\mathrm{C}$ and $\mathrm{N}$ metabolite availability (Stone et al., 2006). It has been proposed that KEG recognizes ABI5 through one or more of its ANK (Ankyrin) repeats (Stone et al., 2006) and its interaction with EDR1 is mediated by the HERC2-like repeats (Gu and Innes, 2011). KEG plays a relevant role in promoting post-germinative growth (Stone et al., 2006). Pointing in this direction is ATL31, a RING-H2-type ubiquitin ligase, which plays a key role in regulating the response to $\mathrm{C} / \mathrm{N}$ conditions during post-germinative growth in Arabidopsis. Under low $\mathrm{C} / \mathrm{N}$ conditions, ATL31 target protein degradation through 26s proteasome pathway entails post-germinative growth. The ATL31 protein localizes to the membrane and recruits target proteins for ubiquitination and degradation by the $26 \mathrm{~S}$ proteasome, allowing seedling development proceed through the early post-germinative growth arrest checkpoint (Sato et al., 2009). Protein kinases catalyze ATL31 phosphorylation, which binds to 14-3-3 proteins and mediates their stability. In low $\mathrm{C} /$ high $\mathrm{N}$ conditions, the protein kinases catalyzing ATL31 phosphorylation are mostly inactivated. In high $\mathrm{C} /$ low $\mathrm{N}$ conditions, these protein kinases are active and catalyze the phosphorylation of 14-3-3 binding sites on ATL31, which binds 14-3-3 proteins and consequently perform their ubiquitination and proteasomal degradation (Yasuda et al., 2014). Studies carried out by Peng et al. (2007) demonstrated that Arabidopsis plants are equipped with a molecular mechanism to adapt to nitrate limitation in which NLA (Nitrogen Limitation Adaptation), a putative RING-type ubiquitin ligase, is involved in the ubiquitination-mediated degradation or modification of substrate protein(s) and function as a positive regulator for the adaptation response to nitrogen limitation.

There are recent experiments pointing out the involvement of specific $\mathrm{ABA}$ and $\mathrm{SnRK} 1 \mathrm{~s}$ signaling pathways in $\mathrm{C} / \mathrm{N}$ response under ABI1 regulation. In high C/low N condition, Lu et al. (2015) identified genes whose expression is upregulated as RD29b, LEA34, and TSPO and suppressed in $A B I 1$ over-expressing plants, whereas other genes as $R A B 18, A R E B 1$, and $A B F 3$, were not affected. Additionally, SNRK1s-responsive genes as DIN6 and SEN5 were downregulated in wild-type plants and this effect was suppressed in $A B I 1$ over-expressing plants. SnRK1s proteins are 
known to phosphorylate several 14-3-3 targeting proteins, which play a role in $\mathrm{C}$ and $\mathrm{N}$ metabolism, such as nitrate reductase (NR) and sucrose 6-phosphate synthase (SPS; Comparot et al., 2003).

Carbon- and nitrogen-signaling pathways interact according to the external $\mathrm{C} / \mathrm{N}$ status and plants have a $\mathrm{C} / \mathrm{N}$ sensing and regulatory mechanism. Genome-wide analysis due to $\mathrm{C}$ and $\mathrm{N}$ signaling interactions in Arabidopsis revealed that $\mathrm{C}$ is a more ubiquitous regulator of the genome than $\mathrm{N}$ (Palenchar et al., 2004). These authors identified 3 MIPS FunCats corresponding to metabolism, protein synthesis and energy genes that are regulated by $\mathrm{C} / \mathrm{N}$ signaling. The accurate regulation of metabolic genes is essential to cope with $\mathrm{C} / \mathrm{N}$ status. The identification of putative cis-acting regulatory elements involved in $\mathrm{C}$ and $\mathrm{N}$ signaling interactions indicates the existence of multiple mechanisms for $\mathrm{C} / \mathrm{N}$ status response. Two transcriptional mechanisms are suggested: (i) independent regulation of C-element and $\mathrm{C}-\mathrm{N}$ element and (ii) dependent regulation of $\mathrm{N}$-dependent enhancer of $\mathrm{C}$ regulation on a $\mathrm{C}$-responsive transcription factor and cis element (Palenchar et al., 2004).

Taken together, a complex picture emerges in which nitrate transporters, glutamate receptors, methyltransferases and ubiquitin ligases are acting on multiple levels to integrate $\mathrm{C}$ and $\mathrm{N}$ signaling interaction pathways and regulate energy and metabolic genes as well as protein expression. An exquisite control comprises of several transcriptional mechanisms assuring an accurate response for the $\mathrm{C} / \mathrm{N}$ status.

\section{CONCLUDING REMARKS}

In this review, we have focused on how changes in $\mathrm{C}$ and $\mathrm{N}$ levels regulate the production of NO, which acts in plant developmental processes through the interaction with phytohormones and other plant growth regulators, using similar molecular elements. Recent investigations have the goal to shed light on the molecular mechanisms underlying the crosstalk of nutrients with NO and $\mathrm{ABA}$ response. This ambitious goal includes several tasks such as analyzing the regulation of $\mathrm{NO}$ and $\mathrm{ABA}$ production by changes in the $\mathrm{C} / \mathrm{N}$ status, the characterization of mutants

\section{REFERENCES}

Abel, S., Nguyen, M. D., and Theologis, A. (1995). The PS-IAA4/5-like family of early auxin-inducible mRNAs in Arabidopsis thaliana. J. Mol. Biol. 251, 533-549. doi: 10.1006/jmbi.1995.0454

Albertos, P., Romero-Puertas, M. C., Tatematsu, K., Mateos, I., Sánchez-Vicente, I., Nambara, E., et al. (2015). S-nitrosylation triggers ABI5 degradation to promote seed germination and seedling growth. Nat Commun. 6, 8669. doi: $10.1038 /$ ncomms 9669

Alboresi, A., Gestin, C., Leydecker, M.-T., Bedu, M., Meyer, C., and Truong H.N. (2005). Nitrate, a signal relieving seed dormancy in Arabidopsis. Plant Cell Environ. 28, 500-512. doi: 10.1111/j.1365-3040.2005.01292.x

Ali-Rachedi, S., Bouinot, D., Wagner, M.-H., Bonnet, M., Sotta, B., Grappin, P., et al. (2004). Changes in endogenous abscisic acid levels during dormancy release and maintenance of mature seeds: studies with the Cape Verde Islands ecotype, the dormant model of Arabidopsis thaliana. Planta 219, 479-488. doi: 10.1007/s00425-004-1251-4

Arroyo Becerra, A., Arenas, F., Jimenez, A., Cantero, A., and Léon-Mejia, P. (2001). "The participation of ABA in the glucose-mediated regulation in Arabidopsis," in Presented at the Twelfth International Conference on Arabidopsis Research, Madison, WI. impaired in either NO or nutrients response (cue1, Atnoa12, nia1nia2, gin5, gin6...), the participation of nutrients in the regulation of lateral root growth by $\mathrm{NO}$ and, finally, the functional characterization of transcription factors responsive to nutrients, $\mathrm{NO}$ and $\mathrm{ABA}$, unraveling their implication in different nutrients signaling pathways. $\mathrm{NO}$ is key to control many of the developmental outcomes in response to $\mathrm{N}, \mathrm{C}$ and $\mathrm{N} / \mathrm{C}$. NO interference on acropetal auxin transport controls root development (Fernández-Marcos et al., 2011) and NO nitrosylates $\mathrm{ABI} 5$ as a regulator to control ABA hormone signaling through its degradation (Albertos et al., 2015). The implementation of the "omics" sciences will help to get insight into the nutrients and hormones crosstalk signaling pathways.

It is important to underline that our current understanding of $\mathrm{C}$ and $\mathrm{N}$-dependent signaling pathways in seeds germination and plant development is mainly related to the model plant Arabidopsis. Therefore, it is necessary to elucidate nutrientsensing and signaling pathways in other plants.

As a useful application of the knowledge of these molecular mechanisms, development of perennial versions of important grain crops is crucial for the increasing worldwide food demand. Root branching order is the main determinant of root trait variation among species (Picon-Cochard et al., 2012) and nutrients can influence root structure. Perennial crops generally have advantages over annuals in maintaining important ecosystem functions, particularly on marginal landscapes or where resources are limited (Tilman et al., 2009). Therefore, identification and molecular characterization of genes involved in nutrients crosstalk with root development signaling pathways could be the basis for the generation of perennial crops through crop breeding.

\section{ACKNOWLEDGMENTS}

This research was supported by grant AGL2012-33268 from the Spanish Ministerio de Economía y Competitividad from the FP7 and The European Regional Development Fund (FEDER) from the European Union.

Baena-González, E., Rolland, F., Thevelein, J. M., and Sheen, J. (2007). A central integrator of transcription networks in plant stress and energy signalling. Nature 448, 938-942. doi: 10.1038/nature06069

Barbier, F., Péron, T., Lecerf, M., Perez-Garcia, M. D., Barrière, Q., Rolčík, J., et al. (2015). Sucrose is an early modulator of the key hormonal mechanisms controlling bud outgrowth in Rosa hybrida. J. Exp. Bot. 66, 2569-2582. doi: 10.1093/jxb/erv047

Bethke, P. C., Badger, M. R., and Jones, R. L. (2004a). Apoplastic synthesis of nitric oxide by plant tissues. Plant Cell 16, 332-341. doi: 10.1105/tpc.017822

Bethke, P. C., Gubler, F., Jacobsen, J. V., and Jones, R. L. (2004b). Dormancy of Arabidopsis seeds and barley grains can be broken by nitric oxide. Planta 219, 847-855. doi: 10.1007/s00425-004-1282-x

Bethke, P. C., Libourel, I. G. L., and Jones, R. L. (2006a). Nitric oxide reduces seed dormancy in Arabidopsis. J. Exp. Bot. 57, 517-526. doi: 10.1093/jxb/ erj060

Bethke, P. C., Libourel, I. G. L., Reinöhl, V., and Jones, R. L. (2006b). Sodium nitroprusside, cyanide, nitrite, and nitrate break Arabidopsis seed dormancy in a nitric oxide-dependent manner. Planta 223, 805-812. doi: 10.1007/s00425-0050116-9

Bethke, P. C., Libourel, I. G. L., Aoyama, N., Chung, Y.-Y., Still, D. W., and Jones, R. L. (2007). The Arabidopsis thaliana aleurone layer responds to nitric oxide, 
gibberellin, and abscisic acid and is sufficient and necessary for seed dormancy. Plant Physiol. 143, 987-1000. doi: 10.1104/pp.106.093435

Bhalerao, R. P., Salchert, K., Bako, L., Okresz, L., Szabados, L., Muranaka, T., et al. (1999). Regulatory interaction of PRL1 WD protein with Arabidopsis SNF1-like protein kinases. Proc. Natl. Acad. Sci. U.S.A. 96, 5322-5327. doi: 10.1073/pnas.96.9.5322

Borisjuk, L., Walenta, S., Rolletschek, H., Mueller-Klieser, W., Wobus, U., and Weber H. (2002). Spatial analysis of plant metabolism: sucrose imaging within Vicia faba cotyledons reveals specific developmental patterns. Plant J. 29, 521-530. doi: 10.1046/j.1365-313x.2002.01222.x

Borisjuk, L., Walenta, S., Weber, H., Mueller-Klieser, W., and Wobus, U. (1998). High-resolution histographical mapping of glucose concentrations in developing cotyledons of Vicia faba in relation to mitotic activity and storage processes: glucose as a possible developmental trigger. Plant J. 15, 583-591. doi: 10.1046/j.1365-313X.1998.00214.x

Bright, J., Desikan, R., Hancock, J. T., Weir, I. S., and Neill, S. J., (2006). ABAinduced NO generation and stomatal closure in Arabidopsis are dependent on $\mathrm{H}_{2} \mathrm{O}_{2}$ synthesis. Plant J. 45, 113-122. doi: 10.1111/j.1365-313X.2005. 02615.x

Cadman, C. S. C., Toorop, P. E., Hilhorst, H. W. M., and Finch-Savage, W. E. (2006). Gene expression profiles of Arabidopsis Cvi seeds during cycling through dormant and non-dormant states indicate a common underlying dormancy control mechanism. Plant J. 46, 805-822. doi: 10.1111/j.1365313X.2006.02738.x

Cao, D., Cheng, H., Wu, W., Soo, H. M., and Peng J. (2006). Gibberellin mobilizes distinct DELLA-dependent transcriptomes to regulate seed germination and floral development in Arabidopsis. Plant Physiol. 142, 509-525. doi: 10.1104/pp.106.082289

Carrera, E., Holman, T., Medhurst, A., Peer, W., Schmuths, H., Footitt, S., et al. (2007). Gene expression profiling reveals defined functions of the ABC transporter COMATOSE late in phase II of germination. Plant Physiol. 143, 1669-1679. doi: 10.1104/pp.107.096057

Chapman, E. J., and Estelle, M. (2009). Mechanism of auxin-regulated gene expression in plants. Ann. Rev. Gen. 43, 265-285. doi: 10.1146/annurev-genet102108-134148

Chen, W. W., Yang, J. L., Qin, C., Jin, C. W., Mo, J. H., Ye, T., et al. (2010). Nitric oxide acts downstream of auxin to trigger root ferric-chelate reductase activity in response to iron deficiency in Arabidopsis. Plant Physiol. 154, 810-819. doi: 10.1104/pp.110.161109

Cho, Y. H., Sheen, J., and Yoo, S. D. (2010). Low glucose uncouples hexokinase1dependent sugar signaling from stress and defense hormone abscisic acid and $\mathrm{C} 2 \mathrm{H} 4$ responses in Arabidopsis. Plant Physiol. 152, 1180-1182. doi: 10.1104/pp.109.148957

Comparot, S., Lingiah, G., and Martin, T. (2003). Function and specificity of 14-3-3 proteins in the regulation of carbohydrate and nitrogen metabolism. J. Exp. Bot. 54, 595-604. doi: 10.1093/jxb/erg057

Coruzzi, G., and Bush, D. R. (2001). Nitrogen and carbon nutrient and metabolite signalling in plants. Plant Physiol. 125, 61-64. doi: 10.1104/pp.1 25.1.61

Coruzzi, G. M., and Zhou, L. (2001). Carbon and nitrogen sensing and signalling in plants: emerging 'matrix effects'. Curr. Opin. Plant Biol. 4, 247-253. doi: 10.1016/S1369-5266(00)00168-0

Cotelle, V., Meek, S. E., Provan, F., Milne, F. C., Morrice, N., and MacKintosh, C. (2000). 14-3-3s regulate global cleavage of their diverse binding partners in sugar-starved Arabidopsis cells. EMBO J. 19, 2869-2876. doi: 10.1093/emboj/19.12.2869

De Lucas, M., and Prat, S. (2014). PIFs get BRright: phytochrome interacting factors as integrators of light and hormonal signals. New Phytol. 202, 1126-1141. doi: 10.1111/nph.12725

Feng, W. L., and Liu, C. M. (1996). Regulation of soil water on the growth and distribution of root system of crops. Res. Ecol. Agro. 3, 5-9.

Fernández-Marcos, M., Sanz, L., Lewis, D. R., Muday, G. K., and Lorenzo, O. (2011). Nitric oxide causes root apical meristem defects and growth inhibition while reducing PIN-FORMED 1 (PIN1)-dependent acropetal auxin transport. Proc. Natl. Acad. Sci. U.S.A. 108, 18506-18511. doi: 10.1073/pnas.1108 644108

Finch-Savage, W. E., Cadman, C. S. C., Toorop, P. E., Lynn, J. R., and Hilhorst, H. W. M. (2007). Seed dormancy release in Arabidopsis Cvi by dry after-ripening, low temperature, nitrate and light shows common quantitative patterns of gene expression directed by environmentally specific sensing. Plant J. 51, 60-78. doi: 10.1111/j.1365-313X.2007.03118.x

Finch-Savage, W. E., and Leubner-Metzger, G. (2006). Seed dormancy and the control of germination. New Phytol. 171, 501-523. doi: 10.1111/j.14698137.2006.01787.x

Finkelstein, R. R., Gampala, S. S. L., and Rock, C. D. (2002). Abscisic acid signalling in seeds and seedlings. Plant Cell 14(Suppl.), S15-S45.

Finnemann, J., and Schjoerring, J. K. (2000). Post-translational regulation of cytosolic glutamine synthetase by reversible phosphorylation and 14-33 protein interaction. Plant J. 24, 171-181. doi: 10.1046/j.1365-313x.2000. 00863.x

Gao, P., Xin, Z., and Zheng, Z.-L. (2008). The OSU1/QUA2/TSD2-encoded putative methyltransferase is a critical modulator of carbon and nitrogen nutrient balance response in Arabidopsis. PLoS ONE 3:e1387. doi: 10.1371/journal.pone.0 001387

Ghillebert, R., Swinnen, E., Wen, J., Vandesteene, L., Ramon, M., Norga, K., et al. (2011). The AMPK/SNF1/SnRK1 fuel gauge and energy regulator: structure, function and regulation. FEBS J. 278, 3978-3990. doi: 10.1111/j.17424658.2011.08315.x

Gibbs, D. J., Md Isa, N., Movahedi, M., Lozano-Juste, J., Mendiondo, G. M., Berckhan, S., et al. (2014). Nitric oxide sensing in plants is mediated by proteolytic control of group VII ERF transcription factors. Mol. Cell. 53, 369-379. doi: 10.1016/j.molcel.2013.12.020

Gibson, S. I., Laby, R. J., and Kim, D. (2001). The sugar-insensitive 1 (sis1) mutant of Arabidopsis is allelic to ctr1. Biochem. Biophys. Res. Commun. 280, 196-203. doi: 10.1006/bbrc.2000.4062

Gu, Y., and Innes, R. W. (2011). The KEEP ON GOING protein of Arabidopsis recruits the ENHANCED DISEASE RESISTANCE1 protein to trans-Golgi network/early endosome vesicles. Plant Physiol. 155, 1827-1838. doi: 10.1104/pp.110.171785

Guérinier, T., Millan, L., Crozet, P., Oury, C., Rey, F., Valot, B., et al. (2013). Phosphorylation of p27(KIP1) homologs KRP6 and 7 by SNF1-related protein kinase-1 links plant energy homeostasis and cell proliferation. Plant J. 75, 515-525. doi: 10.1111/tpj.12218

Gutiérrez, R. A., Lejay, L. V., Dean, A., Chiaromonte, F., Shasha, D. E., and Coruzzi, G. M. (2007). Qualitative network models and genome-wide expression data define carbon/nitrogen-responsive molecular machines in Arabidopsis. Genome Biol. 8, R7. doi: 10.1186/gb-2007-8-1-r7

Hendricks, S. B., and Taylorson, R. B. (1974). Promotion of seed germination by nitrate, nitrite, hydroxylamine, and ammonium salts. Plant Physiol. 54, 304-309. doi: $10.1104 /$ pp.54.3.304

Holdsworth, M. J., Finch-Savage, W. E., Grappin, P., and Job, D. (2007). Postgenomics dissection of seed dormancy and germination. Trends Plant Sci. 13 , 7-13. doi: 10.1016/j.tplants.2007.11.002

Hu, R., Zhu, Y., Shen, G., and Zhang, H. (2014). TAP46 plays a positive role in the ABSCISIC ACID INSENSITIVE5-regulated gene expression in Arabidopsis. Plant Physiol. 164, 721-734. doi: 10.1104/pp.113.2 33684

Ikeda, Y., Men, S., Fischer, U., Stepanova, A. N., Alonso, J. M., Ljung, K., et al. (2009). Local auxin biosynthesis modulates gradient-directed planar polarity in Arabidopsis. Nat. Cell Biol. 11, 731-738. doi: 10.1038/ ncb1879

Kang, J., and Turano, F. J. (2003). The putative glutamate receptor 1.1 (AtGLR1.1) functions as a regulator of carbon and nitrogen metabolism in Arabidopsis thaliana. Proc. Natl. Acad. Sci. U.S.A. 100, 6872-6877. doi: 10.1073/pnas. 1030961100

Kang, J., Mehta, S., and Turano, F. J. (2004). The putative glutamate receptor 1.1 (AtGLR1.1) in Arabidopsis thaliana regulates abscisic acid biosynthesis and signalling to control development and water loss. Plant Cell Physiol. 45, 1380-1389. doi: 10.1093/pcp/pch159

Kiba, T., Feria-Bourrellier, A. B., Lafouge, F., Lezhneva, L., Boutet-Mercey, S., Orsel, M., et al. (2012). The Arabidopsis nitrate transporter NRT2.4 plays a double role in roots and shoots of nitrogen-starved plants. Plant Cell 24, 245-258. doi: 10.1105/tpc.111.092221

Koornneef, M., Bentsink, L., and Hilhorst, H. (2002). Seed dormancy and germination. Curr. Opin. Plant Biol. 5, 33-36. doi: 10.1016/S13695266(01)00219-9

Krapp, A., Hofmann, B., Scha Èfer, C., and Stitt, M. (1993). Regulation of the expression of $\mathrm{rbcS}$ and other photosynthetic genes by carbohydrates: a 
mechanism for the 'sink regulation' of photosynthesis? Plant J. 3, 817-828. doi: 10.1111/j.1365-313X.1993.00817.x

Lastdrager, J., Hanson, J., and Smeekens, S. (2014). Sugar signals and the control of plant growth and development. J. Exp. Bot. 65, 799-807. doi: 10.1093/jxb/ ert474

Lejay, L., Tillard, P., Lepetit, M., Olive, F. D., Filleur, S., Daniel-Vedele, F., et al. (1999). Molecular and functional regulation of two nitrate uptake systems by N- and C- status of Arabidopsis plants. Plant J. 18, 509-519. doi: 10.1046/j.1365313X.1999.00480.X

Libourel, I. G. L., Bethke, P. C., De Michele, R., and Jones, R. L. (2006). Nitric oxide gas stimulates germination of dormant Arabidopsis seeds: use of a flow-through apparatus for delivery of nitric oxide. Planta 223, 813-820. doi: 10.1007/s00425005-0117-8

Lilley, J. L., Gee, C. W., Sairanen, I., Ljung, K., and Nemhauser, J. L. (2012). An endogenous carbon-sensing pathway triggers increased auxin flux and hypocotyl elongation. Plant Physiol. 160, 2261-2270. doi: 10.1104/pp.112.205575

Lioert, F., Casanovas, C., and Penuelas, J. (1999). Seedling survival of Mediterranean shrub land species in relation to root: shoot ratio, seed size and water and nitrogen use. Funct. Ecol. 13, 210-216. doi: 10.1046/j.1365-2435.1999.0 0309.X

Little, D. Y., Rao, H., Oliva, S., Daniel-Vedele, F., Krapp, A., and Malamy, J. E. (2005). The putative high-affinity nitrate transporter NRT2.1 represses lateral root initiation in response to nutritional cues. Proc. Natl. Acad. Sci. U.S.A. 102, 13693-13698. doi: 10.1073/pnas.0504219102

Liu, Y., Shi, L., Ye, N., Liu, R., Jia, W., and Zhang, J. (2009). Nitric oxide-induced rapid decrease of abscisic acid concentration is required in breaking seed dormancy in Arabidopsis. New Phytol. 183, 1030-1042. doi: 10.1111/j.14698137.2009.02899.x

Liu, Z., Zhang, Y., Liu, R., Hao, H., and Wang, Z., Bi, Y. (2011). Phytochrome interacting factors (PIFs) are essential regulators for sucrose-induced hypocotyl elongation in Arabidopsis. J. Plant Physiol. 168, 1771-1779. doi: 10.1016/j.jplph.2011.04.009

Li, Y., Van den Ende, W., and Rolland, F. (2014). Sucrose induction of anthocyanin biosynthesis is mediated by DELLA. Mol. Plant 7, 570-572. doi: $10.1093 / \mathrm{mp} / \mathrm{sst} 161$

Ljung, K., Hull, A. K., Celenza, J., Yamada, M., Estelle, M., Normanly, J., et al. (2005). Sites and regulation of auxin biosynthesis in Arabidopsis roots. Plant Cell 17, 1090-1104. doi: 10.1105/tpc.104.029272

Ljung, K., Nemhauser, J. L., and Perata, P. (2015). New mechanistic links between sugar and hormone signalling networks. Curr. Opin. Plant Biol. 25, 130-137. doi: 10.1016/j.pbi.2015.05.022

Lopez-Molina, L., Mongrand, S., and Chua, N. H. (2001). A postgermination developmental arrest checkpoint is mediated by abscisic acid and requires the ABI5 transcription factor in Arabidopsis. Proc. Natl Acad. Sci. U.S.A. 98, 4782-4787. doi: 10.1073/pnas.081594298

Loreti, E., Povero, G., Novi, G., Solfanelli, C., Alpi, A., and Perata, P. (2008). Gibberellins, jasmonate and abscisic acid modulate the sucrose-induced expression of anthocyanin biosynthetic genes in Arabidopsis. New Phytol. 179, 1004-1016. doi: 10.1111/j.1469-8137.2008.02511.x

Lozano-Juste, J., and León, J. (2010). Nitric oxide modulates sensitivity to ABA. Plant Signal. Behav. 5, 314-316. doi: 10.4161/psb.5.3.11235

Lozano-Juste, J., and León, J. (2011). Nitric oxide regulates DELLA content and PIF expression to promote photomorphogenesis in Arabidopsis. Plant Physiol. 156, 1410-1423. doi: 10.1104/pp.111.177741

Lu, Y., Sasaki, Y., Li, X., Mori, I. C., Matsuura, T., Hirayama, T., et al. (2015). ABI1 regulates carbon/nitrogen-nutrient signal transduction independent of ABA biosynthesis and canonical ABA signalling pathways in Arabidopsis. J. Exp. Bot. 66, 2763-2771. doi: 10.1093/jxb/erv086

Maraschin Fdos, S., Memelink, J., and Offringa, R. (2009). Auxin induced, SCFTIR1-mediated poly-ubiquitination marks AUX/IAA proteins for degradation. Plant J. 59, 100-109. doi: 10.1111/j.1365-313X.2009.03854.x

Matakiadis, T., Alboresi, A., Jikumaru, Y., Tatematsu, K., Pichon, O., Renou, J.-P., et al. (2008). The Arabidopsis abscisic acid catabolic gene CYP707A2 plays a key role in nitrate control of seed dormancy. Plant Physiol. 149, 949-960. doi: 10.1104/pp.108.126938

Moore, B., Zhou, L., Rolland, F., Hall, Q., Cheng, W.-H, Liu, Y.-X, et al. (2003). Role of the Arabidopsis glucose sensor HXK1 in nutrient, light, and hormonal signalling. Science 300, 332-336. doi: 10.1126/science. 1080585
Mouille, G., Ralet, M. C., Cavelier, C., Eland, C., Effroy, D., Hematy, K., et al. (2007). Homogalacturonan synthesis in Arabidopsis thaliana requires a Golgi-localized protein with a putative methyltransferase domain. Plant J. 50, 605-614. doi: 10.1111/j.1365-313X.2007.03086.x

Nakabayashi, K., Okamoto, M., Koshiba, T., Kamiya, Y., and Nambara, E. (2005). Genome-wide profiling of stored mRNA in Arabidopsis thaliana seed germination: epigenetic and genetic regulation of transcription in seed. Plant $J$. 41, 697-709. doi: 10.1111/j.1365-313X.2005.02337.x

Nemeth, K., Selchert, K., Putnoky, P., Bhalerao, R., and Koncz-Kalman, Z. (1998). Pleiotropic control of glucose and hormone responses by PRL1, a nuclear WD protein in Arabidopsis. Genes Dev. 12, 3059-3073. doi: 10.1101/gad.12. 19.3059

Ni, W., Xu, S. L., Tepperman, J. M., Stanley, D. J., Maltby, D. A., Gross, J. D., et al. (2014). A mutually assured destruction mechanism attenuates light signalling in Arabidopsis. Science 344, 1160-1164. doi: 10.1126/science.12 50778

Nozue, K., Covington, M. F., Duek, P. D., Lorrain, S., Fankhauser, C., Harmer, S. L., et al. (2007). Rhythmic growth explained by coincidence between internal and external cues. Nature 448, 358-361. doi: 10.1038/nature05946

Ogawa, M., Hanada, A., Yamauchi, Y., Kuwahara, A., Kamiya, Y., and Yamaguchi, S. (2003). Gibberellin biosynthesis and response during Arabidopsis seed germination. Plant Cell 15, 1591-1604. doi: 10.1105/tpc.011650

Oliveira, I. C., and Coruzzi, G. M. (1999). Carbon and amino acids reciprocally modulate the expression of glutamine synthetase in Arabidopsis. Plant Physiol. 121, 301-310. doi: 10.1104/pp.121.1.301

Orsel, M., Krapp, A., and Daniel-Vedele, F. (2002). Analysis of the NRT2 nitrate transporter family in Arabidopsis. Structure and gene expression. Plant Physiol. 129, 886-896. doi: 10.1104/pp.005280

Osuna, D., Usadel, B., Morcuende, R., Gibon, Y., Bläsing, O. E., Höhne, M., et al. (2007). Temporal responses of transcripts, enzyme activities and metabolites after adding sucrose to carbon-deprived Arabidopsis seedlings. Plant J. 49, 463-491. doi: 10.1111/j.1365-313X.2006.02979.x

Overvoorde, P., Fukaki, H., and Beeckman, T. (2010). Auxin control of root development. Cold Spring Harb. Perspect. Biol. 2, a001537. doi: 10.1101/cshperspect.a001537

Palenchar, P. M., Kouranov, A., Lejay, L. V., and Coruzzi, G. M. (2004). Genomewide patterns of carbon and nitrogen regulation of gene expression validate the combined carbon and nitrogen $(\mathrm{CN})$-signaling hypothesis in plants. Genome Biol. 5, R91. doi: 10.1186/gb-2004-5-11-r91

Paparelli, E., Parlanti, S., Gonzali, S., Novi, G., Mariotti, L., Ceccarelli, N., et al. (2013). Nighttime sugar starvation orchestrates gibberellin biosynthesis and plant growth in Arabidopsis. Plant Cell 25, 3760-3769. doi: 10.1105/tpc.113.115519

Passioura, J. B. (1983). Root and drought resistance. Agric. Water Manage 7, 265-280. doi: 10.1016/0378-3774(83)90089-6

Peng, M., Hudson, D., Schofield, A., Tsao, R., Yang, R., Gu, H., et al. (2008). Adaptation of Arabidopsis to nitrogen limitation involves induction of anthocyanin synthesis which is controlled by the NLA gene. J. Exp. Bot. 59, 2933-2944. doi: 10.1093/jxb/ern148

Peng, M., Hannam, C., Gu, H., Bi, Y.-M., and Rothstein, S.-J. (2007). A mutation in NLA, which encodes a RING-type ubiquitin ligase, disrupts the adaptability of Arabidopsis to nitrogen limitation. Plant J. 50, 320-337. doi: 10.1111/j.1365313X.2007.03050.x

Petersson, S. V., Johansson, A. I., Kowalczyk, M., Makoveychuk, A., Wang, J. Y., Moritz, T., et al. (2009). An auxin gradient and maximum in the Arabidopsis root apex shown by high-resolution cell-specific analysis of IAA distribution and synthesis. Plant Cell 21, 1659-1668. doi: 10.1105/tpc.109.066480

Picon-Cochard, C., Pilon, R., Tarroux, E., Pagès, L., Robertson, J., and Dawson, L. (2012). Effect of species, root branching order and season on the root traits of 13 perennial grass species. Plant Soil 353, 47-57. doi: 10.1007/s11104-011$1007-4$

Price, J., Laxmi, A., St Martin, S. K., and Jang, J. C. (2004). Global transcription profiling reveals multiple sugar signal transduction mechanisms in Arabidopsis. Plant Cell 16, 2128-2150. doi: 10.1105/tpc.104.022616

Price, J., Li, T.-C., Kang, S. G., Na, J. K., and Jang, J.-C. (2003). Mechanisms of glucose signalling during germination of Arabidopsis. Plant Physiol. 132, 1424-1438. doi: 10.1104/pp.103.020347

Proels, R. K., and Roitsch, T. (2009). Extracellular invertase LIN6 of tomato: a pivotal enzyme for integration of metabolic, hormonal, and stress 
signals is regulated by a diurnal rhythm. J. Exp. Bot. 60, 1555-1567. doi: 10.1093/jxb/erp027

Purcell, P. C., Smith, A. M., and Halford, N. G. (1998). Antisense expression of a sucrose non-fermenting-1-related protein kinase expression in potato results in decreased expression of sucrose synthase in tubers and loss of sucroseinducibility of sucrose synthase transcripts in leaves. Plant J. 14, 195-202. doi: 10.1046/j.1365-313X.1998.00108.x

Ribeiro, D. M., Araujo, W. L., Fernie, A. R., Schippers, J. H., and Mueller-Roeber, B. (2012). Translatome and metabolome effects triggered by gibberellins during rosette growth in Arabidopsis. J. Exp. Bot. 63, 2769-2786. doi: 10.1093/jxb/ err463

Riou-Khamlichi, C., Menges, M., Healy, J. M. S., and Murray, J. A. H. (2000). Sugar control of the plant cell cycle: differential regulation of Arabidopsis D-type cyclin gene expression. Mol. Cell Biol. 20, 4513-4521. doi: 10.1128/MCB.20.13.45134521.2000

Robert, H. S., and Friml, J. (2009). Auxin and other signals on the move in plants. Nat. Chem. Biol. 5, 325-332. doi: 10.1038/nchembio.170

Rodrigues, A., Adamo, M., Crozet, P., Margalha, L., Confraria, A., Martinho, C., et al. (2013). ABI1 and PP2CA phosphatases are negative regulators of Snf1related protein kinase1 signaling in Arabidopsis. Plant Cell 25, 3871-3884. doi: $10.1105 /$ tpc. 113.114066

Roitsch, T., and González, M.-C. (2004). Function and regulation of plant invertases: sweet sensations. Trends Plant Sci. 9, 606-613. doi: 10.1016/j.tplants.2004.10.009

Rook, F., Gerrits, N., Kortstee, A., van Kampen, M., Borrias, M., Weisbeek, P., et al. (1998a). Sucrose-specific signalling represses translation of the Arabidopsis ATB2 bZIP transcription factor gene. Plant J. 15, 253-263. doi: 10.1046/j.1365313X.1998.00205.X

Rook, F., Weisbeek, P., and Smeekens, S. (1998b). The light-regulated Arabidopsis bZIP transcription factor gene ATB2 encodes a protein with an unusually long leucine zipper domain. Plant Mol. Biol. 37, 171-178. doi: 10.1023/A:1005964327725

Ross, J. J., Murfet, I. C., and Reid, J. B. (1997). Gibberellin mutants. Physiol. Plant. 100, 550-560. doi: 10.1111/j.1399-3054.1997.tb03060.x

Sairanen, I., Novák, O., Pěnčík, A., Ikeda, Y., Jones, B., Sandberg, G., et al. (2012). Soluble carbohydrates regulate auxin biosynthesis via PIF proteins in Arabidopsis. Plant Cell 24, 4907-4916. doi: 10.1105/tpc.112. 104794

Sanz, L., Albertos, P., Mateos, I., Sánchez-Vicente, I., Lechón, T., FernándezMarcos, M., et al. (2015). Nitric oxide (NO) and phytohormones crosstalk during early plant development. J. Exp. Bot. 66, 2857-2868. doi: 10.1093/jxb/ erv213

Sarath, G., Bethke, P. C., Jones, R., Baird, L. M., Hou, G., and Mitchell, R. B. (2005). Nitric oxide accelerates seed germination in warm-season grasses. Planta 21, 1-11. doi: 10.1007/s00425-005-0162-3

Sato, T., Maekawa, S., Yasuda, S., Sonoda, Y., Katoh, E., Ichikawa, T., et al. (2009). CNI1/ATL31, a RING-type ubiquitin ligase that functions in the carbon/nitrogen response for growth phase transition in Arabidopsis seedlings. Plant J. 60, 852-864. doi: 10.1111/j.1365-313X.2009.04006.x

Scheible, W. R., Morcuende, R., Czechowski, T., Fritz, C., Osuna, D., PalaciosRojas, N., et al. (2004). Genome-wide reprogramming of primary and secondary metabolism, protein synthesis, cellular growth processes, and the regulatory infrastructure of Arabidopsis in response to nitrogen. Plant Physiol. 136, 2483-2499. doi: 10.1104/pp.104.047019

Schepetilnikov, M., Dimitrova, M., Mancera-Martínez, E., Geldreich, A., Keller, M., and Ryabova, L. A. (2013). TOR and S6K1 promote translation reinitiation of uORF-containing mRNAs via phosphorylation of eIF3h. EMBO J. 32, 1087-1102. doi: 10.1038/emboj.2013.61

Signora, L., De Smet, I., Foyer, C. H., and Zhang, H. (2001). ABA plays a central role in mediating the regulatory effects of nitrate on root branching in Arabidopsis. Plant J. 28, 655-662. doi: 10.1046/j.1365-313x.2001. 01185.x

Stewart, J. L., Maloof, J. N., and Nemhauser, J. L. (2011). PIF genes mediate the effect of sucrose on seedling growth dynamics. PLoS ONE 6:e19894. doi: 10.1371/journal.pone.0019894

Stone, S. L., Williams, L. A., Farmer, L. M., Vierstra, R. D., and Callis, J. (2006). KEEP ON GOING, a RING E3 ligase essential for Arabidopsis growth and development, is involved in abscisic acid signaling. Plant Cell 18, 3415-3428. doi: $10.1105 /$ tpc. 106.046532
Swarup, K., Benková, E., Swarup, R., Casimiro, I., Péret, B., Yang, Y., et al. (2008). The auxin influx carrier LAX3 promotes lateral root emergence. Nat. Cell Biol. 10, 946-954. doi: $10.1038 /$ ncb1754

Terrile, M. C., Paris, R., Calderon-Villalobos, L. I., Iglesias, M. J., Lamattina, L., Estelle, M., et al. (2012). Nitric oxide influences auxin signalling through $S$-nitrosylation of the Arabidopsis TRANSPORT INHIBITOR RESPONSE 1 auxin receptor. Plant J. 70, 492-500. doi: 10.1111/j.1365-313X.2011.04885.x

Tilman, D., Socolow, R., Foley, J., Hill, J., Larson, E., Lynd, L., et al. (2009). Beneficial biofuels-the food, energy, and environment trilemma. Science 325, 270. doi: $10.1126 /$ science. 1177970

Touraine, B. (2004). Nitrogen acquisition and assimilation in higher plants: nitrate uptake by roots-transporters and root development. Plant Ecophysiol. 3, 1-34. doi: 10.1007/978-1-4020-2728-4_1

Ubeda-Tomás, S., Swarup, R., Coates, J., Swarup, K., Laplaze, L., Beemster, G. T., et al. (2008). Root growth in Arabidopsis requires gibberellin/DELLA signalling in the endodermis. Nat. Cell Biol. 10, 625-628. doi: 10.1038/ncb1726

Weltmeier, F., Rahmani, F., Ehlert, A., Dietrich, K., Schütze, K., Wang, X., et al. (2009). Expression patterns within the Arabidopsis C/S1 bZIP transcription factor network: availability of heterodimerization partners controls gene expression during stress response and development. Plant Mol. Biol. 69, 107-119. doi: 10.1007/s11103-008-9410-9

Wiese, A., Christ, M. M., Virnich, O., Schurr, U., and Walter, A. (2007). Spatiotemporal leaf growth patterns of Arabidopsis thaliana and evidence for sugar control of the diel leaf growth cycle. New Phytol. 174, 752-761. doi: 10.1111/j.1469-8137.2007.02053.x

Wiese, A., Elzinga, N., Wobbes, B., and Smeekens, S. (2005). Sucrose-induced translational repression of plant bZIP-type transcription factors. Biochem. Soc. Trans. 33, 272-275. doi: 10.1042/BST0330272

Wilkinson, J. Q., and Crawford, N. M. (1993). Identification and characterization of a chlorate-resistant mutant of Arabidopsis thaliana with mutations in both nitrate reductase structural genes NIA1 and NIA2. Mol. Gen. Genet. 239, 289-297.

Wind, J. J., Peviani, A., Snel, B., Hanson, J., and Smeekens, S. C. (2013). ABI4: versatile activator and repressor. Trends Plant Sci. 18, 125-132. doi: 10.1016/j.tplants.2012.10.004

Xiao, W., Sheen, J., and Jang, J.-C. (2000). The role of hexokinase in plant sugar signal transduction and growth and development. Plant Mol. Biol. 44, 451-461. doi: 10.1023/A:1026501430422

Xu, J., Wang, W., Yin, H., Liu, X., Sun, H., and Mi, Q. (2010). Exogenous nitric oxide improves antioxidative capacity and reduces auxin degradation in roots of Medicago truncatula seedlings under cadmium stress. Plant Soil 326, 321-330. doi: 10.1007/s11104-009-0011-4

Yadav, U. P., Ivakov, A., Feil, R., Duan, G. Y., Walther, D., Giavalisco, P., et al. (2014). The sucrose-trehalose 6-phosphate (Tre6P) nexus: specificity and mechanisms of sucrose signalling by Tre6P. J. Exp. Bot. 65, 1051-1068. doi: 10.1093/jxb/ert457

Yamagishi, K., Tatematsu, K., Yano, R., Preston, J., Kitamura, S., Takahashi, H., et al. (2009). CHOTTO1, a double AP2 domain protein of Arabidopsis thaliana, regulates germination and seedling growth under excess supply of glucose and nitrate. Plant Cell Physiol. 50, 330-340. doi: 10.1093/pcp/pcn201

Yamaguchi, S., and Kamiya, Y. (2002). Gibberellins and light-stimulated seed germination. J. Plant Growth Regul. 20, 369-376. doi: 10.1007/s003440 010035

Yasuda, S., Sato, T., Maekawa, S., Aoyama, S., Fukao, Y., and Yamaguchi, J. (2014). Phosphorylation of Arabidopsis ubiquitin ligase ATL31 is critical for plant carbon/nitrogen nutrient balance response and controls the stability of 14-3-3 proteins. J. Biol. Chem. 289, 15179-15193. doi: 10.1074/jbc.M113.533133

Yu, X., Sukumaran, S., and Márton, L. (1998). Differential expression of the Arabidopsis Nial and Nia2 genes: cytokinin-induced nitrate reductase activity is correlated with increased Nial transcription and mRNA levels. Plant Physiol. 116, 1091-1096. doi: 10.1104/pp.116.3.1091

Zhang, H., and Forde, B. (1998). An Arabidopsis MADS box gene that controls nutrient induced changes in root architecture. Science 279, 407-409. doi: 10.1126/science.279.5349.407

Zhang, Y., Primavesi, L. F., Jhurreea, D., Andralojc, P. J., Mitchell, R. A., Powers, S. J., et al. (2009). Inhibition of SNF1-related protein kinase1 activity and regulation of metabolic pathways by trehalose-6-phosphate. Plant Physiol. 149, 1860-1871. doi: $10.1104 /$ pp.108.133934

Zhao, M.-G., Liu, R.-J, Chen, L., Tian, Q.-Y., and Zhang, W.-H. (2008). Glucose-induced inhibition of seed germination in Lotus japonicus is 
alleviated by nitric oxide and spermine. J. Plant Physiol. 166, 213-218. doi: 10.1016/j.jplph.2008.03.001

Zheng, Z.-L. (2009). Carbon and nitrogen nutrient balance signalling in plants. Plant Signal. Behav. 4, 584-591. doi: 10.4161/psb.4.7.8540

Zhong, S. W., Shi, H., Xue, C., Wang, L., Xi, Y., Li, J., et al. (2012). A molecular framework of light-controlled phytohormone action in Arabidopsis. Curr. Biol. 22, 1530-1535. doi: 10.1016/j.cub.2012.06.039

Zhuo, D., Okamoto, M., Vidmar, J., and Glass, A. D. (1999). Regulation of a putative high affinity nitrate transporter (Nrt2:1 At) in roots of Arabidopsis thaliana. Plant J. 17, 563-568. doi: 10.1046/j.1365-313X.1999.00396.x
Conflict of Interest Statement: The authors declare that the research was conducted in the absence of any commercial or financial relationships that could be construed as a potential conflict of interest.

Copyright $\odot 2015$ Osuna, Prieto and Aguilar. This is an open-access article distributed under the terms of the Creative Commons Attribution License (CC BY). The use, distribution or reproduction in other forums is permitted, provided the original author(s) or licensor are credited and that the original publication in this journal is cited, in accordance with accepted academic practice. No use, distribution or reproduction is permitted which does not comply with these terms. 